\title{
GPs' attitudes, awareness, and practice regarding early diagnosis of dementia
}

\author{
Shamail Ahmad, Martin Orrell, Steve Iliffe and Antonia Gracie
}

\begin{abstract}
Background

In primary care, the diagnosis of dementia is often delayed and the 2007 National Audit Office Report concluded action was needed to improve patient care and value for money.
\end{abstract}

Aim

To investigate the attitudes, awareness, and practice of GPs in England regarding early diagnosis and management of patients with dementia, and perceptions of local specialist services, to identify training or support needs.

Design of study

Secondary analysis of survey data that capture the above attitudes, awareness, and practice.

Setting

Online survey, targeting GP members of medeConnect. Method

Survey data were obtained using an anonymised online self-completion questionnaire, and then analysed using standard data-analysis software.

\section{Results}

A total of 1011 GPs across the eight English regions responded. Older GPs were more confident in diagnosing and giving advice about dementia, but less likely to feel that early diagnosis was beneficial, and more likely to feel that patients with dementia can be a drain on resources with little positive outcome. Younger GPs were more positive and felt that much could be done to improve quality of life. Attitudes had no correlation with sex. GPs in general felt they had not had sufficient basic and post-qualifying training in dementia, and overall knowledge about dementia was low.

\section{Conclusion}

Much could be done to improve GPs' knowledge of dementia, and the confidence of older GPs could be an educational resource. However, greater experience may create scepticism about early diagnosis because of the perceived poor quality of specialist services.

Keywords

dementia; early diagnosis; family practice.

\section{INTRODUCTION}

In 2006-2007 there were around 560000 people with dementia in England, some $1.1 \%$ of the total population. A worldwide ageing population means that dementia presents a public health challenge not just in England but around the world. Across England, however, between 51\% (aged >80 years) and 62\% (aged 65-69 years) of people with dementia never have their condition diagnosed, and many only receive a diagnosis once the disease has progressed beyond the early stages. ${ }^{1}$

There is a broad consensus that early identification of dementia symptoms and appropriate interventions tailored to the individual are mainly beneficial, leading to improved outcomes for people with dementia and their family carers. There are good practice examples of early intervention and evidence to support their wider application. The National Audit Office found, for example, that the Croydon Memory Service has doubled the numbers of people with dementia being assessed, and helped to overcome the stigma attached to referral for dementia. Without a diagnosis, interventions, services, and support cannot be offered. ${ }^{1,2}$ In response to the report of the Committee of Public Accounts, Improving Services and Support for People with Dementia, published in

S Ahmad, BA, ACA, A Gracie, BSc, ACA, National Audit Office, Health VFM, London. M Orrell, BMedSci, PhD, FRCPsych, professor in psychiatry, Department of Mental Health Sciences; S Iliffe, FRCGP, FRCP, PCOP director, Primary Care \& Population Health, University College London, London.

\section{Address for correspondence}

Shamail Ahmad, National Audit Office, Health VFM, 157-197 Buckingham Palace Road, London, SW1W 9SP. E-mail: shamail.ahmad@nao.gsi.gov.uk

Submitted: 25 January 2010; Editor's response: 22 February 2010; final acceptance: 25 March 2010.

(C) British Journal of General Practice

This is the full-length article of an abridged version published in print. Cite this article as: Br J Gen Pract 2010; DOI: 10.3399/bjgp10X515386. 
January $2008,{ }^{3}$ and the National Audit Office's earlier report on the same subject in July 2007,'1 the English Department of Health has now published a National Dementia Strategy ${ }^{4}$ recognising the need for action on 17 key objectives including good quality early diagnosis and intervention for all.

The reported time taken to diagnose Alzheimer's disease, after first noticing symptoms, is longer in the UK (32 months) than in France (24 months), Spain (18 months), Italy (14 months), or Germany (10 months). ${ }^{5}$ GPs are the gateway to diagnosis but their attitudes and skills can actually be a barrier to accessing services.

The National Audit Office undertook a national study of dementia services across England in 2009, using the same questionnaire used by the Audit Commission, ${ }^{6}$ and derived from an earlier trial, ${ }^{7}$ to measure GPs' attitudes, practice, confidence, and knowledge about caring for patients with dementia.

\section{METHOD}

The present study was designed to determine whether GPs' views on early diagnosis, their attitudes generally towards dementia, and their knowledge of dementia were related to their age (using their year of qualification as a proxy) or sex. The study objective was to identify whether there was a need for tailored education, training, or support aimed at particular sections of the GP population to help change perceptions and drive an improvement in the rate of diagnosis and interventions.

\section{How this fits in}

There is strong evidence that diagnosis of dementia is often very delayed, which impacts on the care received and quality of life of the person with dementia. The National Dementia Strategy, launched in February 2009, seeks to address these issues. However, this research shows that implementation of the National Dementia Strategy may require enhancement in specialist services to improve performance in primary care. GPs, particularly older ones, require an awareness of what can be done and the potential benefits.

The parts of the questionnaire relating to attitude and perspectives on services (see Table 1 for the topics covered) required answers on a 5-point scale from strongly agree to strongly disagree. For the purposes of analysis, agree/strongly agree responses were grouped together. Since dementia is within the normal remit of a GP, if they did not express an opinion (that is, selected neither agree nor disagree), it was assumed they did not know the answer. The knowledge quiz section (Appendix 1) used a 4-point multiple-choice scale with only one correct answer to each of 10 questions; correct answers accrued 1 point and were summed to create an unweighted score.

\section{Hypotheses}

The study hypotheses were:

1. Recent graduates will be more likely to believe that they can have an impact on their patients'

\section{Table 1. Odds ratios of recent graduates agreeing with the statements, compared with those who} graduated before 1990.

\begin{tabular}{|c|c|c|c|c|c|}
\hline Statement & Date qualified & Agree, $n(\%)$ & Disagree, $n(\%)$ & Odds ratio & $95 \% \mathrm{Cl}$ \\
\hline \multirow[t]{2}{*}{ 1. It is important to look actively for early signs of dementia } & Pre 1990 & $250(87.4)$ & $36(12.6)$ & 2.38 & 1.83 to 2.93 \\
\hline & 1990 or later & $380(94.3)$ & $23(5.7)$ & & \\
\hline \multirow[t]{2}{*}{ 2. It is beneficial to make an early diagnosis of dementia } & Pre 1990 & $285(86.1)$ & 46 (13.9) & 2.43 & 1.93 to 2.93 \\
\hline & 1990 or later & $407(93.7)$ & $27(6.3)$ & & \\
\hline \multirow{2}{*}{$\begin{array}{l}\text { 3. I use specific tests and/or protocols to help me diagnose } \\
\text { and manage dementia }\end{array}$} & Pre 1990 & $266(79.4)$ & $69(20.6)$ & 1.20 & 0.82 to 1.57 \\
\hline & 1990 or later & $300(82.2)$ & $65(17.8)$ & & \\
\hline \multirow{2}{*}{$\begin{array}{l}\text { 4. I have ready access to specialist advice to help me } \\
\text { diagnose and manage dementia }\end{array}$} & Pre 1990 & $309(84.0)$ & $59(16.0)$ & 0.75 & 0.38 to 1.12 \\
\hline & 1990 or later & $314(79.7)$ & $80(20.3)$ & & \\
\hline \multirow{2}{*}{$\begin{array}{l}\text { 5. There are satisfactory specialist services in my area } \\
\text { to meet the needs of those with dementia }\end{array}$} & Pre 1990 & $149(47.6)$ & $164(52.4)$ & 1.02 & 0.71 to 1.32 \\
\hline & 1990 or later & $166(48.0)$ & $180(52.0)$ & & \\
\hline \multirow{2}{*}{$\begin{array}{l}\text { 6. I have received sufficient basic and post-qualifying } \\
\text { training to help me to diagnose and manage dementia }\end{array}$} & Pre 1990 & $136(48.9)$ & $142(51.1)$ & 1.16 & 0.84 to 1.47 \\
\hline & 1990 or later & $176(52.5)$ & $159(47.5)$ & & \\
\hline \multirow{2}{*}{$\begin{array}{l}\text { 7. Providing a patient with a diagnosis is usually more } \\
\text { helpful than harmful }\end{array}$} & Pre 1990 & $245(77.3)$ & $72(22.7)$ & 0.78 & 0.44 to 1.13 \\
\hline & 1990 or later & $272(72.7)$ & $102(27.3)$ & & \\
\hline \multirow[t]{2}{*}{ 8. Managing dementia is more often frustrating than rewarding } & Pre 1990 & $172(58.1)$ & $124(41.9)$ & 0.83 & 0.52 to 1.15 \\
\hline & 1990 or later & $181(53.6)$ & $157(46.4)$ & & \\
\hline \multirow{2}{*}{$\begin{array}{l}\text { 9. Much can be done to improve the quality of life of people } \\
\text { with dementia }\end{array}$} & Pre 1990 & 214 (70.2) & $91(29.8)$ & 1.52 & 1.18 to 1.87 \\
\hline & 1990 or later & 294 (78.2) & $82(21.8)$ & & \\
\hline \multirow{2}{*}{$\begin{array}{l}\text { 10. Patients with dementia can be a drain on resources with } \\
\text { little positive outcome }\end{array}$} & Pre 1990 & $128(42.2)$ & $174(57.6)$ & 0.63 & 0.31 to 0.96 \\
\hline & 1990 or later & $104(31.8)$ & $223(68.2)$ & & \\
\hline
\end{tabular}


wellbeing, because they are more aware of therapeutic options.

2. Older graduates will have established moreeffective working relationships with specialist services, and rate them as more accessible and of better quality.

3. Older graduates will be less likely to believe that early detection is beneficial.

4. Older graduates will be less likely to believe that sharing the diagnosis with the patient is beneficial.

The survey was carried out between 24 June and 8 July 2009 by medeConnect, the market research division of doctors.net.uk, a free network with 167536 General Medical Council (GMC)-registered UK doctors enrolled, of whom 29939 are GPs. Members self-select to participate in market research, and are offered incentives dependent on the complexity of the survey, length of time needed, and specialty of members; 4616 GPs had registered an interest in online market research at the time of this survey. In this survey, GP responders were offered 1000 electronic Surfing Reward (eSR) points, equating to $£ 5$, to complete a 10-minute survey; eSR points can be accumulated and turned into retail vouchers or donated to charity. Sampling for the survey was quota based, using the regional distribution of GPs by strategic health authority contained in the NHS Workforce statistics.

Bivariate analyses were carried out, using SPSS and Excel software, comparing responses to statements or questions on attitudes towards and confidence about aspects of dementia care in those who qualified before 1990 and those who qualified subsequently. This dichotomy was chosen for two reasons:

- The accumulation of experience through clinical work is likely to be important in a condition like dementia syndrome, with its low incidence of 1.5 cases per 2000 registered patients in a demographically average area. Those qualifying in 1990 would be likely to have a maximum of just

Table 2. Regional breakdown of survey responders.

\begin{tabular}{lcc} 
Region & Number of responders & Percentage of total, \% $(n=1011)$ \\
\hline South East & 221 & 21.9 \\
\hline North West & 128 & 12.7 \\
\hline Northern & 117 & 11.6 \\
\hline Eastern & 116 & 11.5 \\
\hline South West & 116 & 11.5 \\
\hline Trent & 116 & 11.5 \\
\hline Greater London & 109 & 10.8 \\
\hline West Midlands & 88 & 8.7
\end{tabular}

over 10 years' experience at the time of the 2006 survey. Those qualified before 1990 represent a group with longer experience in general practice.

- The GP contract changed in 1990 in a way that could have promoted the recognition of dementia syndrome, through the '75 and over checks'. Although this component of the contract was abandoned in 2004, financial incentives for dementia care were introduced as part of the Quality and Outcomes Framework (QOF) in 2006. GPs in training would have been prepared for contractual changes, while their older colleagues would have had to adapt to them.

Similar bivariate analyses were carried out by participants' sex, because a previous study had suggested a sex difference.

\section{RESULTS}

In the event, 1011 GPs completed the survey questionnaire, with at least $9 \%$ of the total coming from each of eight English regions. The survey covered all of the regions across England well, in terms of responder participation (Table 2). The South East region contributed the greatest number of responders, representing $22 \%$ of the sample overall. The time period during which the largest proportion of responders (35\%) qualified was the 1990 s, and the sex split was $57 \%$ male, $43 \%$ female.

\section{Attitudes and perceptions of services}

Table 1 shows that hypothesis 1 was supported. Responses to statements 9 and 10 suggest that more recent graduates appear to be less likely to exhibit 'therapeutic nihilism' and are more likely to believe that they can have an impact on their patients' wellbeing. The hypothesis that older graduates will rate specialist services as more accessible and of better quality than do more recent graduates (hypothesis 2) was not supported, there being no significant difference between the groups. Half of responders did not think that their local specialist services were satisfactory, which deserves further investigation. The hypothesis that older graduates will be less likely to believe that early detection is beneficial (hypothesis 3 ) was supported by responses to statements 1 and 2, but hypothesis 4 (older graduates will be less likely to believe that sharing the diagnosis with the patient is beneficial) was not supported, and there was no difference between the groups.

Because previous work had suggested that female GPs were less likely to be nihilistic about dementia diagnosis and management, the same bivariate analysis was performed comparing responses by sex. There were no statistically significant differences 
between female and male responses, except that female GPs were significantly less likely to agree that they had sufficient basic and post-qualifying training $(110 / 250,44 \%$, odds ratio [OR] 0.63, 95\% confidence interval $[\mathrm{Cl}]=0.30$ to 0.95 ) compared with their male colleagues (202/363, $55.6 \%)$.

\section{Confidence}

Responders were asked: 'How confident are you in diagnosing dementia?'. Those who graduated before 1990 were significantly more likely to say they were confident $(324 / 465,69.7 \%)$ compared with more recent graduates $(264 / 545,48.4 \%$, OR $0.41,95 \% \mathrm{Cl}$ $=0.15$ to 0.67 )

Responders were also asked: 'How confident are you in giving advice about managing dementiarelated symptoms?'. Those who graduated before 1990 were significantly more likely to say they were confident (237/466, 50.9\%) compared with more recent graduates $(174 / 545,31.9 \%$, OR $0.45,95 \% \mathrm{Cl}$ $=0.20$ to 0.71 ).

Female GPs were significantly less likely to say that they were confident in diagnosing dementia (190/431, 44.1\%, OR 0.36, $95 \% \mathrm{Cl}=0.10$ to 0.62 ) compared with their male colleagues (398/580, $68.6 \%$ ). Female GPs were also significantly less likely to say that they were confident in giving advice about managing dementia-related symptoms (115/431, 26.7\%, OR $0.35,95 \% \mathrm{Cl}=0.08$ to 0.62 ) compared with their male colleagues $(296 / 580$, $51.0 \%)$

\section{Knowledge}

Overall knowledge of dementia was low; $52 \%$ of those qualifying before 1990 scored between 0 and 2 out of 10 , as did $58 \%$ of those graduating later. There was no statistically significant difference between men (53\% scored two or less) and women (58\%).

\section{DISCUSSION}

\section{Summary of main findings}

GPs who qualified before 1990 exhibited greater pessimism about the importance of looking actively for early signs of dementia and about the benefits of making an early diagnosis of dementia. In comparison with the more recently qualified GPs, older GPs appeared significantly more likely to feel that patients with dementia could be a drain on resources with little positive outcome; this may reflect accumulated negative experiences of seeking help from other services. However, confidence in diagnosing dementia, giving advice about it, and managing dementia-related symptoms was significantly greater in those who graduated before 1990, perhaps reflecting their increased experience in managing patients with dementia; this is compatible with their more negative attitude towards patients with dementia, because different aspects of experience are being measured. Levels of knowledge of dementia were low, and were unrelated to qualification before or after 1990, or to sex.

\section{Limitations of the study}

Opinion surveys ask questions that can be interpreted differently by different responders, which means that the findings of this online study should be treated with some caution. However, they do conform to the general critical perspective on the quality of dementia care expressed by the National Dementia Strategy, suggesting that variation in subjective impressions may not be a major biasing factor. Similarly, the self-selected sample (members of doctors.net), the incentive to participate in the survey, and its online format may have introduced selection biases, making it unwise to generalise from these results. However, the findings are similar to those from other studies using samples recruited in different ways, ${ }^{7,8}$ so, the view of the study is that the selection biases are probably small.

The question about satisfactory specialist services did not seek further details, so it is not known whether responders interpreted this to mean social care as well as specialist medical care.

\section{Comparison with existing literature}

A specific problem with dementia is that some patients, families, and professionals are reluctant to diagnose dementia, and GPs may unconsciously hesitate to label a patient with dementia. ${ }^{9}$ As a consequence, dementia is probably underdiagnosed and under-treated, with an estimated $50 \%$ of primary care patients over 65 years of age with dementia not diagnosed by their primary care practitioners. ${ }^{10}$

Renshaw et al found that almost half of GPs surveyed did not believe it was beneficial to make an early diagnosis, ${ }^{8}$ but in areas where there had been specific efforts to contact and educate local GPs they were far more likely to believe in the value of early diagnosis. Turner et al (2004, using data from 2002) also found that more experienced (particularly male) GPs were more pessimistic about dementia care, as were those with lower knowledge about dementia as measured by a knowledge quiz. ${ }^{7}$ They also found that those GPs who were less confident/knowledgeable about dementia were also less likely to support open communication with patients about the dementia diagnosis. They concluded that educational support should concentrate on epidemiological knowledge, disclosure of diagnosis, and management of behaviour problems. 
These unfavourable views of primary care performance in the diagnosis and management of dementia should be set against positive evidence of GP engagement in redesign of dementia services, in collaboration with specialist colleagues. ${ }^{11,12}$ Beattie and colleagues have also noted the incongruence between positive commitment to good quality care for patients with dementia and poor or non-existent specialist services. ${ }^{13}$

\section{Implications for clinical practice}

The findings of this research are most relevant to the implementation of the recently launched National Dementia Strategy. There is evidently considerable developmental work to be done in general practice to enhance knowledge and work through attitudinal barriers to the primary care of dementia. In its 2007 report, the National Audit Office recommended that the Department of Health work with Skills for Health, Skills for Care, the GMC, and the Royal Colleges to improve the coverage of dementia in undergraduate and postgraduate medical and nursing training. They found at that time that Skills for Health had yet to establish how to work with commissioners and workforce developers on how training and workforce development should respond to the ageing population or develop new training. The same points are raised in the National Dementia Strategy. One point that the findings of the present study adds is that those GPs who have been qualified longer have more confidence in working with people with dementia, and are therefore a potential educational resource.

However, the paradox in these findings is that those most confident in the diagnosis and management of patients with dementia (the group that qualified before 1990) are least convinced that their early identification is worthwhile, and more likely to feel that these patients drain resources. In addition to the possible role of stigma among older GPs, the interpretation of this by this study is that the accumulated experience of the problems of providing care for people with dementia creates both confidence and a degree of resignation, the latter being due to the lack of resources available to support dementia care in the community. The finding that less than half of responders agreed that 'there are satisfactory specialist services in my area to meet the needs of those with dementia' supports this interpretation. Those implementing the National Dementia Strategy might consider the possibility that the improvement of primary care performance may depend, in part, on the improvement of specialist services.

\section{Funding body}

This research was funded by the National Audit Office, which audits central government accounts and reports to Parliament on the value for money achieved by government projects and programmes. The National Audit Office's budget is set by Parliament. The National Audit Office and its head, the Comptroller and Auditor General, have comprehensive statutory rights of access to the bodies they audit.

\section{Ethical approval}

Not applicable.

\section{Competing interests}

The authors have stated that there are none.

\section{Acknowledgements}

The authors would like to thank all the GPs who participated in this survey and also Andrew Epps and Clare Rapkins for their assistance.

\section{Discuss this article}

Contribute and read comments about this article on the Discussion Forum: http://www.rcgp.org.uk/bjgp-discuss

\section{REFERENCES}

1. National Audit Office. Improving services and support for people with dementia: report by the Comptroller and Auditor General. London: Stationery Office, 2007. http://www.officialdocuments.gov.uk/document/hc0607/hc06/0604/0604.pdf (accessed 23 Jul 2010).

2. Department of Health. A recipe for care - not a single ingredient. Clinical case for change: Report by Professor Ian Philp. London: DoH, 2007.

http://www.dh.gov.uk/prod_consum_dh/groups/dh_digitalassets/@d h/@en/documents/digitalasset/dh_065227.pdf (accessed 23 Jul 2010).

3. House of Commons Committee of Public Accounts. Improving services and support for people with dementia. Sixth Report of Session 2007-08. London: Stationery Office, 2008.

http://www.publications.parliament.uk/pa/cm200708/cmselect/cmpu bacc/228/228.pdf (accessed 10 Aug 2010).

4. Department of Health. Living well with dementia: a National Dementia Strategy. London: DoH, 2009.

http://www.dh.gov.uk/prod_consum_dh/groups/dh_digitalassets/@d h/@en/documents/digitalasset/dh_094051.pdf (accessed 23 Jul 2010).

5. Alzheimer's Disease International. Facing Dementia survey: identifying critical barriers to optimal care. London: ADI, 2005. http://www.alz.co.uk/media/dementiasurvey.html (accessed $23 \mathrm{Jul}$ 2010).

6. Anderson D. Forget me not - mental health services for older people. London: Audit Commission. 2000.

7. Turner S, Iliffe S, Downs M, et al. General practitioners' knowledge, confidence and attitudes in the diagnosis and management of dementia. Age Ageing 2004; 33(5): 461-467.

8. Renshaw J, Scurfield P, Cloke L, Orrell M. General practitioners' views on the early diagnosis of dementia. Br J Gen Pract 2001 51(462): 37-38.

9. Downs M, Bowers B. Caring for people with dementia. BMJ 2008; 336(7638): 225-226.

10. Boustani M, Peterson B, Hanson L, et al. Screening for dementia in primary care: a summary of the evidence for the US preventive services task force. Ann Intern Med 2003; 138(11): 927-937.

11. Greaves I, Jolley D. National Dementia Strategy: well intentioned but how well founded and how well directed? Br J Gen Pract 2010; 60(572): 193-198.

12. Koch T, Iliffe S. Implementing the National Dementia Strategy in England: evaluating innovative practices using a case study methodology. Dementia 2010; in press.

13. Beattie A, Daker-White G, Gillard J, Means R. 'They don't quite fit the way we organise our services': results from a UK field study of marginalised groups in dementia care. Disabil Soc 2005; 20: 67-68. 


\section{Appendix 1. GP knowledge quiz (correct answers highlighted in bold).}

\section{Question 1}

A GP with a list of 1500-2000 people can expect to have the following number of people with dementia on their list:
A. 1-6
B. $7-11$
C. $12-20$
D. $\geq 21$

Question 2

By 2021, prevalence of dementia in the general population in the UK is expected to:
A. Decrease slightly
B. Remain approximately the same
C. Increase slightly
D. Nearly double

Question 3

One of the risk factors for the development of Alzheimer's disease is:
A. Hardening of arteries
B. Age
C. Nutritional deficiencies
D. Exposure to aluminium

\section{Question 4}

Which of the following procedures is required to definitely confirm that symptoms are due to dementia?
A. Mini-Mental State Exam
B. Post mortem
C. CAT scan of the brain
D. Blood test

\section{Question 5}

Which of the following sometimes resembles dementia?
A. Depression
B. Acute confusional state
C. Stroke
D. All of the above

\section{Question 6}

Which of the following clinical findings best differentiates vascular dementia from Alzheimer's?
A. Word-finding problems
B. Short-term (2-minute span) visual memory loss
C. Stepwise disease course
D. Presence of depression

\section{Question 7}

Which statement is true concerning the treatment of dementia patients who are depressed?
A. It is usually useless to treat them for depression because feelings of sadness and inadequacy are part of the disease

B. Treatments for depression may be effective in alleviating depressive symptoms

C. Antidepressant medication should not be prescribed

D. Proper medication may alleviate symptoms of depression and prevent further intellectual decline.

\section{Question 8}

Which of the following best describes the functions of the Alzheimer's Society?
A. Central research, information and campaigning role
B. Provision of local support and education to carers
C. Providing day and home care for dementia patients
D. All of the above 